\title{
Preface: Flood-risk analysis and integrated management
}

\author{
Philip Bubeck ${ }^{1}$, Jeroen C. J. H. Aerts ${ }^{3}$, Hans de Moel ${ }^{3}$, and Heidi Kreibich ${ }^{2}$ \\ ${ }^{1}$ University of Potsdam, Institute of Earth and Environmental Science, Karl-Liebknecht-Strasse 24-25, \\ 14476 Potsdam, Germany \\ ${ }^{2}$ Helmholtz Centre Potsdam, GFZ German Research Centre for Geosciences, Section 5.4 Hydrology, \\ Telegrafenberg, 14473 Potsdam, Germany \\ ${ }^{3}$ Institute for Environmental Studies (IVM), VU University Amsterdam, the Netherlands
}

Correspondence to: Philip Bubeck (bubeck@uni-potsdam.de)

Published: 20 April 2016

\section{Introduction}

Despite significant efforts at the local, national, and global levels to reduce the negative impacts from natural hazards, global flood losses have been increasing in recent decades, and floods remain the most destructive and frequent natural hazards in the world (World Bank, 2012). In Europe alone, floods between 1970 and 2015 affected more than 16 million people and caused the death of 4682 people according to the EM-DAT database (Guha-Sapir et al., 2015; retrieved by the authors on 10 February 2016). Single flood events such as the one in 2013 along the Elbe and Danube river in Germany can cause EUR billions of losses and can have severe impacts on the flood-affected population, transportation systems and business operations (Thieken et al., 2016; DKKV, 2015). Increasing flood losses in the past have been mainly attributed to the growing amount of people and economic assets in flood-prone regions (Barredo, 2009; Bouwer, 2010). Despite the risk of flooding, the latter provide otherwise favourable conditions, such as access to fresh water and means for transportation (Kummu et al., 2011). In the future, the trend in increasing losses could be further aggravated due to the increasing frequency and intensity of some climate related hazards in several regions (IPCC, 2013). For instance, flood frequencies along the Rhine, Europe's largest and economically most important river, could increase in coming decades owing to the effects of global warming on water resources (te Linde et al., 2010).

In light of continuously high flood losses, traditional flood protection strategies that primarily focused on prevention by means of flood defense structures such as dikes have been increasingly challenged and replaced by integrated risk management concepts in Europe and many other countries (Bubeck et al., 2015). These integrated concepts take into account that flood defenses can fail and therefore complement traditional flood protection with additional policies and measures (including e.g. zoning, building codes, flood insurance) that aim at alleviating the residual risk, i.e. potential flood impacts, such as loss of life, economic or cultural losses.

This shifted focus towards the risk of flooding ( $=$ probability $\times$ exposure $\times$ vulnerability) poses distinct challenges for both, scientific approaches to analyse and assess the multi-faceted aspects of flood-risk and its integrated management. Traditional protection strategies primarily required scientific insights into hazard frequencies, design discharge levels and technical knowledge for the construction of flood defense infrastructure. Flood hazard assessment and management then was mainly a task of engineers, hydrologists and statisticians (Merz et al., 2014).

In integrated flood-risk management strategies, a plethora of additional aspects comprising the entire risk chain need to be considered: in addition to hazard analysis, insights are required into people, environmental goods and services, economic assets and the cultural heritage potentially exposed to floods (e.g. Fuchs et al., 2015) and the vulnerability of the exposed elements in case a flood occurs, such as residential buildings (e.g. Elmer et al., 2010). Moreover, there is an increasing demand for risk assessments that evaluate insights into hazards, consequences and vulnerabilities in an integrated way (Aerts et al., 2014; Thieken et al., 2014; Merz et al., 2014). Also, a good understanding of perceptual and behavioural aspects, possibly leading to higher or lower exposure and vulnerabilities, is needed for a comprehensive and sustainable risk management (Ludy and Kon- 
dolf, 2012; Bubeck et al., 2012, 2013; Kreibich et al., 2011, 2015; Collenteur et al., 2014; Holub et al., 2011; Di Baldassarre et al., 2013). Further complexity is added by the (projected) changes in climate, exposure and vulnerability (Merz et al., 2014; Bubeck et al., 2011; Jongman et al., 2015). Besides, the shift to integrated flood-risk management has significantly enlarged the number of stakeholders that need to be involved and "managed" themselves. This includes, among others, citizens, spatial planners, environmentalists, professional associations and public authorities. In Europe, for instance, participation is now also formally required in accordance with Article 9(3) of the EU Floods Directive (EC 2007/60), which requires "the active involvement of all interested parties [...]" (Newig et al., 2014; Albrecht, 2016).

The special issue "Flood risk analysis and integrated management", which was organized in the aftermath of the 2nd European Conference on FLOODrisk Management, aimed at providing a series of contributions that address these diverse topics, covering a wide range of different geographic regions.

\section{Research contributions}

\subsection{Hazard analysis}

The analysis of the flood hazard in terms of frequencies, severity and the technical flood defense infrastructure remains an important topic also in integrated risk concepts and was also covered in the present special issue. The paper by Hamdi et al. (2014) shows a comparison of three statistical approaches to extreme value analysis: the annual maxima (AM), the peaks-over-threshold (POT) and the $r$ largest order statistics ( $r$-LOS). These methods are applied to measured surge levels at the French coast, where several nuclear facilities are located that are designed to withstand (unlikely) occurrences of failure. Nevertheless, recent extreme events showed exceptional observed surges (outliers), which were much larger than other observations. This clearly illustrated the potential to underestimate extreme water levels calculated with the current statistical methods. It was found that the $r$-LOS and POT methods have reduced the uncertainty on the distribution parameters and return level estimates and have systematically shown values of the 100- and 500-year return levels smaller than those estimated with the AM method. Findings are of practical relevance, not only to nuclear energy operators in France, for applications in stormsurge hazard analysis and flood management, but also for the optimal planning and design of facilities to withstand extreme environmental conditions, with an appropriate level of risk.

Shortly after a flood event, data and particularly maps about the flood and its consequences are scarce and not readily available. Therefore, Nazir et al. (2015) developed a three-step approach for the rapid generation of improved flood maps on basis of aperture radar images. In the first step, the pre- and post-flood images are adaptively histogram equalized. In the second step, the hidden details in difference image are enhanced using contrast-based enhancement and histogram smoothing. In the third step, the flood map is generated using equalized pre-, post- and difference images. Simulation results show an improved visualisation by maintaining the natural smoothness. Validations of the new approach were successfully undertaken. Rapid evaluations based on reliable inundation maps of flood events can support an efficient response both in emergency management and in financial compensation and reconstruction planning.

Floods following a dike breach can be especially disastrous and pose a risk to economic assets and life, given the potentially fast-rising water levels (Miller et al., 2015). The breach development process and the flow and sediment transport after a levee breach due to overtopping was examined by Dou et al. (2014). To explore the breach development process, a flow and sediment model was established using twodimensional shallow water equations. Moreover, the lateral widening of the breach was both modelled and tested in a laboratory experiment. The latter confirmed the validity of the simulations in terms of the flow and sediment transport processes. A better understanding of the processes following a levee breach can support the development of measures that help to reduce loss of life and damage to economic assets.

\subsection{Exposure and vulnerability analysis}

Since a residual risk of flooding always remains even in the presence of flood protection infrastructure, good insights into elements that are exposed to flooding as well as changes in exposure over time are crucial for an effective disaster risk management and financing. Jongman et al. (2014) provide an analysis on changes in flood exposure in the Netherlands and discuss the implications for the management of the financial risk. They show that there has been a rapid increase in flood exposure in recent decades, with faster growth rates in terms of building stock and its economic value in flood-prone areas compared with regions not at risk. It is argued that this will have negative implications for the private insurance market - currently considered as complementary strategy in the Netherlands - because the total financial risk is growing and would need to be covered by rising premiums.

In line with the shift to integrated risk management, which also takes potential consequences into account, flood damage assessments and modelling have gained growing importance (Merz et al., 2013; Kellermann et al., 2015; Bouwer et al., 2009). Even though existing damage models are often derived from damage data collected in a certain geographical region, they are widely applied also to case studies. This assumes that the empirically derived damage functions are transferable to other geographical regions, even though these might differ in terms of building characteristics and thus vulnerability. To what extent loss functions can be transferred and applied to other case studies was investigated by Cam- 
merer et al. (2013), who test the performance of several flood damage functions when applied to a simulated flood event in Austria. They find that flood damage functions that were derived from regions that resemble the case study considerably outperform functions from other regions. The findings indicate that geographical origin is an important criterion for the selection of a damage model for integrated risk assessments.

Three contributions of this special issue take a closer look into the flood vulnerability of the built environment. The vulnerability of different economic assets to flood impacts is very heterogeneous, even within the same category such as buildings (Merz et al., 2010). For a comprehensive risk analysis, insights into specific vulnerabilities are therefore needed but have received relatively little attention in the literature, so far. In their article, Stephenson and D' Ayala (2014) develop a new approach to evaluate the vulnerability of historic buildings in England, which has become a concern for those in charge of the preservation of the built cultural heritage. Also the EU Floods Directive (2007/60/EC) requires member states in accordance with Article 2(2) to indicate the risk to cultural heritage in their hazard and risk maps. A synthetic vulnerability function for historical buildings was derived and tested that takes both engineering judgement on the response of the building but also the perceived economic and historic value of the building into account. An application of the developed approach to three case studies in England showed that the procedure is able to capture individual building and site-wide vulnerability.

While various methods were previously developed to assess the flood vulnerability and damage to buildings and critical infrastructures, only few approaches are available for a pre-event assessment of built-up areas with a high resolution. In their contribution, Blanco-Vogt and Schanze (2014) provide a conceptual and methodological framework to understand and assess the physical flood susceptibility of buildings. Using remote sensing data, buildings are extracted in a semi-automatic way and subsequently systematically characterized on the basis of a building taxonomy, comprising, among other things, the height of the building, its size, and the roof form. Based on this characterization, the physical susceptibility is evaluated using depth-impact functions. The developed approach is applied to the case study of Magangue, which is a city along the Magdalena River in Colombia. Results from such an analysis of physical flood susceptibility can be used to prepare detailed civil engineering analyses in hotspot areas as well as vulnerability analyses additionally comprising social and economic aspects.

A new method to assess the damage-reducing effect of flood-mitigation measures implemented by private households is provided by Hudson et al. (2014). The shift to integrated risk management requires all stakeholders to play a role in managing risk, and each stakeholder should act in line with their abilities. Therefore, accurate estimates of the damage reduction potential of household-level measures is required. Hudson et al. (2014) present propensity score match- ing as a more refined evaluation method to provide more sensitive estimates of the effectiveness of damage mitigation measures. The key refinement is in controlling for sources of bias caused by risk characteristics that differ systematically between households. A systematic difference implies that comparisons of those who employ measures and those who do not, produce less reliable estimates. In Hudson et al. (2014) propensity score matching was applied to survey data from flood-affected households across Germany. They detect a substantial overestimate of mitigation measures' effectiveness if bias is not controlled for, ranging from nearly EUR 1700 to 15000 per measure. Still, bias-corrected estimates show a high degree of effectiveness of private floodmitigation measures implemented at the building level, preventing between EUR 6700 and 14000 of flood damage per flood event.

\subsection{Integrated risk assessments}

Several contributions of this special issue provide advances in integrated risk assessments, combining information on hazards, impacts and vulnerabilities. A new method for assessing societal flood-fatality risks in river deltas is presented in the contribution of de Bruijn et al. (2014). Floodrisk analyses of river deltas are complex because the effects from storm surges and river discharges or a combination of both may cause flooding. In addition, the effect of upstream breaches on downstream water levels and flood risk must be taken into account. De Bruijn et al. (2014) present a Monte Carlo-based flood-risk analysis framework for policy making, which considers both storm surges and river flood waves and includes effects from hydrodynamic interaction on flood risk. The outputs are FN curves (which give the annual probability of an event with $\mathrm{N}$ or more fatalities) potential loss of life (expected annual number of fatalities) for the area as a whole, and the contributions of the three subzones (tidal, non-tidal and transition zone) to the total risk in the delta. The framework was applied to analyse societal flood fatality risk in the Rhine-Meuse delta. The method, however, can be applied to other deltas, as well. It is especially suitable for flood management of large deltas with a developed infrastructure of flood defenses, where hydrodynamic interactions are important.

Also the contribution by Miller et al. (2015) addresses the risk to life due to flooding in a delta area - in this case, New Orleans. Since the catastrophic flooding of New Orleans due to Hurricane Katrina in 2005, the city's hurricane protection system has been improved to provide protection against a hurricane load with a $1 / 100$ per year exceedance frequency. In a flood-risk analysis, the probabilities and consequences of various flood scenarios were analysed for the central area of New Orleans to give an estimate of the risk to life in the post-Katrina situation. A hydrodynamic model has been used to simulate flood characteristics of various levee breaches. Results indicate that - depending on the flood scenario - the 
estimated loss of life in case of flooding ranges from about 100 to nearly 500 , with the highest life loss due to breaching of the river levees leading to large flood depths. The risk estimates are combined to determine the individual risk and societal risk for New Orleans. When compared to risks of other large-scale engineering systems (e.g., other flood prone areas, dams and the nuclear sector) and acceptable risk criteria found in literature, the risks are relatively high - despite the recent major improvements to the flood protection system.

An approach to explore the influence of sea-level rise and socioeconomic developments on flood risk for the floodprone District 4 in Ho Chi Minh City is provided by Lasage et al. (2014). They show that expected annual damage (EAD) in this district could rise from USD 0.31 million to up to USD 0.78 million in 2100 . They also find that rising sea level has a larger effect on the EAD than socioeconomic developments. The results stress the importance of such comprehensive risk assessments for the sustainable development of rapidly developing coastal cities like Ho Chi Minh City.

\subsection{Management and stakeholder participation}

Finally, three contributions focus on flood-risk management aspects. In addition to providing an approach to explore the impacts of sea-level rise and socioeconomic developments on flood risk in Ho Chi Minh City, Lasage et al. (2014) develop and evaluate the effects of different adaptation strategies like new levees, dry and wet proofing of buildings and elevating roads and buildings. The benefit-cost ratios and net present values for the adaptation strategies were estimated until 2100 . The adaptation strategies wet proofing and dry proofing generated the best results. The provided study will also have practical implications as the government of Ho Chi Minh City will use the generated information on the different strategies for the development of a new flood protection strategy.

The opportunities and challenges associated with multifunctional dikes in the Netherlands is investigated by van Loon-Steensma and Vellinga (2014). They review possible additional functions as well as strengths, weaknesses, and threats associated with robust flood defences in rural riverine areas. Besides undertaking an extensive literature review, they analysed case studies at five locations where dike reinforcement was planned. For each of the case studies, semistructured interviews with experts and stakeholders were conducted. At each of the five locations, suitable robust flood defences could be identified that would additionally contribute to the envisaged various functions and ambitions for the respective areas. Primary strengths of a robust, multifunctional dike in comparison to a traditional dike appeared to be the more efficient use of space due to the combination of different functions, a longer-term focus and greater safety.

The purchase of flood insurance has been proposed as one solution to lower the vulnerability of households at risk of flooding because it reduces the financial consequences for an individual in case of a flood. However, practical experience also shows that flood-prone households often do not voluntarily purchase flood insurance, even if cost-effectiveness is given (Kunreuther, 1996). In their contribution, Aliagha et al. (2014) examine factors that influence homeowners to purchase flood insurance in Johor, Malaysia. Using discriminant analysis, they identify the demand-side factors that best explain the purchase of flood insurance and risk aversion. They identify considerable differences between those who buy insurance and those who do not. The most important differences between the two groups were found in terms of prior flood experience, perceived price of insurance cover, trust in the reliability of the insurer, distance to the river and income.

\section{Concluding remarks}

The contributions of the special issue "Flood risk analysis and integrated management" provide novel insights into the diverse aspects that need to be taken into account in integrated flood-risk management. In addition to having a good understanding of the hazard component, which remains an important topic, also insights into exposure and vulnerability as well as flood-risk management are required. The contributions also demonstrate the complexities that arise from the implementation of such integrated concepts, both in terms of analysis and management. For example, implementing retention areas to temporarily store flood water to safeguard low-lying vulnerable areas elsewhere often competes with other users, who claim the same areas for other land-use functions (Aerts et al., 2005). By providing new insights and novel methodological approaches to tackle these complexities in very diverse geographical regions - including Colombia, Vietnam, Malaysia, the US and European case studies this special issue aimed at contributing to a more comprehensive and sustainable flood-risk management.

\section{References}

Aerts, J., Van Herwijnen, M., Janssen, R., and Stewart, T.: Evaluating spatial design techniques for solving land-use allocation problems, J. Environ. Plann. Man., 48, 121-142, 2005.

Aerts, J. C. J. H., Botzen, W. J. W., Emanuel, K., Lin, N., de Moel, H., and Michel-Kerjan, E. O.: Evaluating Flood Resilience Strategies for Coastal Megacities, Science, 344, 473-475, 2014.

Albrecht, J.: Legal framework and criteria for effectively coordinating public participation under the Floods Directive and Water Framework Directive: European requirements and German transposition, Environ. Sci. Policy, 55, 368-375, doi:10.1016/j.envsci.2015.07.019, 2016.

Aliagha, U. G., Jin, T. E., Choong, W. W., Nadzri Jaafar, M., and Ali, H. M.: Factors affecting flood insurance purchase in residential properties in Johor, Malaysia, Nat. Hazards Earth Syst. Sci., 14, 3297-3310, doi:10.5194/nhess-14-3297-2014, 2014. 
Barredo, J. I.: Normalised flood losses in Europe: 1970-2006, Nat. Hazards Earth Syst. Sci., 9, 97-104, doi:10.5194/nhess-9-972009, 2009.

Blanco-Vogt, A. and Schanze, J.: Assessment of the physical flood susceptibility of buildings on a large scale - conceptual and methodological frameworks, Nat. Hazards Earth Syst. Sci., 14, 2105-2117, doi:10.5194/nhess-14-2105-2014, 2014.

Bouwer, L. M.: Have Disaster Losses Increased Due to Anthropogenic Climate Change?, B. Am. Meteorol. Soc., 92, 39-46, 2010.

Bouwer, L. M., Bubeck, P., Wagtendonk, A. J., and Aerts, J. C. J. H.: Inundation scenarios for flood damage evaluation in polder areas, Nat. Hazards Earth Syst. Sci., 9, 1995-2007, doi:10.5194/nhess9-1995-2009, 2009.

Bubeck, P., de Moel, H., Bouwer, L. M., and Aerts, J. C. J. H.: How reliable are projections of future flood damage?, Nat. Hazards Earth Syst. Sci., 11, 3293-3306, doi:10.5194/nhess-11-32932011, 2011.

Bubeck, P., Botzen, W. J. W., and Aerts, J. C. J. H.: A Review of Risk Perceptions and Other Factors that Influence Flood Mitigation Behavior, Risk Anal., 32, 1481-1495, 2012.

Bubeck, P., Botzen, W. J. W., Kreibich, H., and Aerts, J. C. J. H.: Detailed insights into the influence of flood-coping appraisals on mitigation behaviour, Global Environ. Chang., 23, 1327-1338, 2013.

Bubeck, P., Kreibich, H., Penning-Rowsell, E. C., Botzen, W. J. W., de Moel, H., and Klijn, F.: Explaining differences in flood management approaches in Europe and in the USA - a comparative analysis, Journal of Flood Risk Management, doi:10.1111/jfr3.12151, online first, 2015.

Cammerer, H., Thieken, A. H., and Lammel, J.: Adaptability and transferability of flood loss functions in residential areas, Nat. Hazards Earth Syst. Sci., 13, 3063-3081, doi:10.5194/nhess-133063-2013, 2013.

Collenteur, R. A., de Moel, H., Jongman, B., and Di Baldassarre, G.: The failed-levee effect: Do societies learn from flood disasters?, Nat. Hazards, 76, 373-388, 2014.

de Bruijn, K. M., Diermanse, F. L. M., and Beckers, J. V. L.: An advanced method for flood risk analysis in river deltas, applied to societal flood fatality risk in the Netherlands, Nat. Hazards Earth Syst. Sci., 14, 2767-2781, doi:10.5194/nhess-14-27672014, 2014.

Di Baldassarre, G., Viglione, A., Carr, G., Kuil, L., Salinas, J. L., and Blöschl, G.: Socio-hydrology: conceptualising humanflood interactions, Hydrol. Earth Syst. Sci., 17, 3295-3303, doi:10.5194/hess-17-3295-2013, 2013.

DKKV: Das Hochwasser im Juni 2013 - Bewährungsprobe für das Hochwasserrisikomanagement in Deutschland, DKKVSchriftenreihe Nr. 53, Bonn, 2015.

Dou, S.-T., Wang, D.-W., Yu, M.-H., and Liang, Y.-J.: Numerical modeling of the lateral widening of levee breach by overtopping in a flume with $180^{\circ}$ bend, Nat. Hazards Earth Syst. Sci., 14, 11-20, doi:10.5194/nhess-14-11-2014, 2014.

Elmer, F., Thieken, A. H., Pech, I., and Kreibich, H.: Influence of flood frequency on residential building losses, Nat. Hazards Earth Syst. Sci., 10, 2145-2159, doi:10.5194/nhess-10-21452010, 2010.

Fuchs, S., Keiler, M., and Zischg, A.: A spatiotemporal multihazard exposure assessment based on property data, Nat. Haz- ards Earth Syst. Sci., 15, 2127-2142, doi:10.5194/nhess-152127-2015, 2015.

Guha-Sapir, D., Below, R., and Hoyois, P.: EM-DAT: International Disaster Database, Université Catholique de Louvain, Brussels, Belgium, 2015.

Hamdi, Y., Bardet, L., Duluc, C.-M., and Rebour, V.: Extreme storm surges: a comparative study of frequency analysis approaches, Nat. Hazards Earth Syst. Sci., 14, 2053-2067, doi:10.5194/nhess-14-2053-2014, 2014.

Holub, M., Suda, J., and Fuchs, S.: Mountain hazards: reducing vulnerability by adapted building design, Environmental Earth Sciences, 66, 1853-1870, 2011.

Hudson, P., Botzen, W. J. W., Kreibich, H., Bubeck, P., and Aerts, J. C. J. H.: Evaluating the effectiveness of flood damage mitigation measures by the application of propensity score matching, Nat. Hazards Earth Syst. Sci., 14, 1731-1747, doi:10.5194/nhess-14-1731-2014, 2014.

IPCC: Climate Change 2013: The Physical Science Basis, Contribution of Working Group I to the Fith Assessment Report of the Intergovernmental Panel on Climate Change, Cambridge, United Kingdom and New York, NY, USA, 2013.

Jongman, B., Koks, E. E., Husby, T. G., and Ward, P. J.: Increasing flood exposure in the Netherlands: implications for risk financing, Nat. Hazards Earth Syst. Sci., 14, 1245-1255, doi:10.5194/nhess-14-1245-2014, 2014.

Jongman, B., Winsemius, H. C., Aerts, J. C., de Perez, E. C., van Aalst, M. K., Kron, W., and Ward, P. J.: Declining vulnerability to river floods and the global benefits of adaptation, P. Natl. Acad. Sci. USA, 112, E2271-E2280, doi:10.1073/pnas.1414439112, 2015.

Kellermann, P., Schöbel, A., Kundela, G., and Thieken, A. H.: Estimating flood damage to railway infrastructure - the case study of the March River flood in 2006 at the Austrian Northern Railway, Nat. Hazards Earth Syst. Sci., 15, 2485-2496, doi:10.5194/nhess-15-2485-2015, 2015.

Kreibich, H., Christenberger, S., and Schwarze, R.: Economic motivation of households to undertake private precautionary measures against floods, Nat. Hazards Earth Syst. Sci., 11, 309-321, doi:10.5194/nhess-11-309-2011, 2011.

Kreibich, H., Bubeck, P., Van Vliet, M., and De Moel, H.: A review of damage-reducing measures to manage fluvial flood risks in a changing climate, Mitigation and Adaptation Strategies for Global Change, 20, 967-989, 2015.

Kummu, M., de Moel, H., Ward, P. J., and Varis, O.: How Close Do We Live to Water? A Global Analysis of Population Distance to Freshwater Bodies, PLoS ONE, 6, e20578, doi:10.1371/journal.pone.0020578, 2011.

Kunreuther, H.: Mitigating disaster losses through insurance, J. Risk Uncertainty, 12, 171-187, 1996.

Lasage, R., Veldkamp, T. I. E., de Moel, H., Van, T. C., Phi, H. L., Vellinga, P., and Aerts, J. C. J. H.: Assessment of the effectiveness of flood adaptation strategies for HCMC, Nat. Hazards Earth Syst. Sci., 14, 1441-1457, doi:10.5194/nhess-14-14412014, 2014.

Ludy, J. and Kondolf, G. M.: Flood risk perception in lands "protected” by 100-year levees, Nat. Hazards, 61, 829-842, 2012.

Merz, B., Kreibich, H., Schwarze, R., and Thieken, A.: Review article "Assessment of economic flood damage", Nat. Hazards 
Earth Syst. Sci., 10, 1697-1724, doi:10.5194/nhess-10-16972010, 2010.

Merz, B., Kreibich, H., and Lall, U.: Multi-variate flood damage assessment: a tree-based data-mining approach, Nat. Hazards Earth Syst. Sci., 13, 53-64, doi:10.5194/nhess-13-53-2013, 2013.

Merz, B., Aerts, J., Arnbjerg-Nielsen, K., Baldi, M., Becker, A., Bichet, A., Blöschl, G., Bouwer, L. M., Brauer, A., Cioffi, F., Delgado, J. M., Gocht, M., Guzzetti, F., Harrigan, S., Hirschboeck, K., Kilsby, C., Kron, W., Kwon, H.-H., Lall, U., Merz, R., Nissen, K., Salvatti, P., Swierczynski, T., Ulbrich, U., Viglione, A., Ward, P. J., Weiler, M., Wilhelm, B., and Nied, M.: Floods and climate: emerging perspectives for flood risk assessment and management, Nat. Hazards Earth Syst. Sci., 14, 19211942, doi:10.5194/nhess-14-1921-2014, 2014.

Miller, A., Jonkman, S. N., and Van Ledden, M.: Risk to life due to flooding in post-Katrina New Orleans, Nat. Hazards Earth Syst. Sci., 15, 59-73, doi:10.5194/nhess-15-59-2015, 2015.

Nazir, F., Riaz, M. M., Ghafoor, A., and Arif, F.: Brief Communication: Contrast-stretching- and histogram-smoothnessbased synthetic aperture radar image enhancement for flood map generation, Nat. Hazards Earth Syst. Sci., 15, 273-276, doi:10.5194/nhess-15-273-2015, 2015.

Newig, J., Challies, E., Jager, N., and Kochskämper, E.: What Role for Public Participation in Implementing the EU Floods Directive? A Comparison With the Water Framework Directive, Early Evidence from Germany and a Research Agenda, Environmental Policy and Governance, 24, 275-288, 2014.
Stephenson, V. and D'Ayala, D.: A new approach to flood vulnerability assessment for historic buildings in England, Nat. Hazards Earth Syst. Sci., 14, 1035-1048, doi:10.5194/nhess-14-10352014, 2014.

te Linde, A. H., Aerts, J. C. J. H., Bakker, A. M. R., and Kwadijk, J. C. J.: Simulating low-probability peak discharges for the Rhine basin using resampled climate modeling data, Water Resour. Res., 46, W03512, doi:10.1029/2009WR007707, 2010.

Thieken, A. H., Cammerer, H., Dobler, C., Lammel, and J., Schöberl, F.: Estimating changes in flood risks and benefits of non-structural adaptation strategies - a case study from Tyrol, Austria, Mitigation and Adaptation Strategies for Global Change, 1-34, doi:10.1007/s11027-014-9602-3, online first, 2014.

Thieken, A. H., Bessel, T., Kienzler, S., Kreibich, H., Müller, M., Pisi, S., and Schröter, K.: The flood of June 2013 in Germany: how much do we know about its impacts?, Nat. Hazards Earth Syst. Sci. Discuss., doi:10.5194/nhess-2015-324, in review, 2016.

van Loon-Steensma, J. M. and Vellinga, P.: Robust, multifunctional flood defenses in the Dutch rural riverine area, Nat. Hazards Earth Syst. Sci., 14, 1085-1098, doi:10.5194/nhess-14-10852014, 2014.

World Bank 2012: Cities and Flooding: A guide to Integrated Urban Flood Risk Management for the 21st Century, The World Bank/GFDRR Washington, D.C., 2012. 